\title{
Improved performance of diatomite-based dental nanocomposite ceramics using layer-by-layer assembly
}

This article was published in the following Dove Press journal:

International Journal of Nanomedicine

2 May 2012

Number of times this article has been viewed

\author{
Xiaoli Lu ${ }^{1,2}$ \\ Yang Xia' \\ Mei Liu' \\ Yunzhu Qian ${ }^{3}$ \\ Xuefeng Zhou ${ }^{4}$ \\ Ning $\mathrm{Gu}^{4}$ \\ Feimin Zhang ${ }^{1,4}$ \\ 'Institute of Stomatology, Nanjing \\ Medical University, Nanjing, \\ ${ }^{2}$ Nantong Stomatological Hospital, \\ Nantong, ${ }^{3}$ Center of Stomatology, \\ The Second Affiliated Hospital of \\ Suzhou University, Suzhou, ${ }^{4}$ Suzhou \\ Institute, Southeast University, \\ Suzhou, People's Republic of China
}

Correspondence: Feimin Zhang Institute of Stomatology, Nanjing Medical University, I 36 Hanzhong Road, Nanjing 210029, People's Republic of China

Tel +86 I380I589779

Fax +862586516414

Email fmzhang@njmu.edu.cn
Abstract: To fabricate high-strength diatomite-based ceramics for dental applications, the layer-by-layer technique was used to coat diatomite particles with cationic [poly(allylamine hydrochloride)] and anionic [poly(sodium 4-styrenesulfonate)] polymers to improve the dispersion and adsorption of positively charged nano- $\mathrm{ZrO}_{2}$ (zirconia) as a reinforcing agent. The modified diatomite particles had reduced particle size, narrower size distribution, and were well dispersed, with good adsorption of nano- $\mathrm{ZrO}_{2}$. To determine the optimum addition levels for nano- $\mathrm{ZrO}_{2}$, ceramics containing $0,20,25,30$, and $35 \mathrm{wt} \%$ nano- $\mathrm{ZrO}_{2}$ were sintered and characterized by the three-point bending test and microhardness test. In addition to scanning electron microscopy, propagation phase-contrast synchrotron X-ray microtomography was used to examine the internal structure of the ceramics. The addition of $30 \mathrm{wt} \%$ nano- $\mathrm{ZrO}_{2}$ resulted in the highest flexural strength and fracture toughness with reduced porosity. Shear bond strength between the core and veneer of our diatomite ceramics and the most widely used dental ceramics were compared; the shear bond strength value for the diatomite-based ceramics was found to be significantly higher than for other groups $(P<0.05)$. Our results show that diatomite-based nanocomposite ceramics are good potential candidates for ceramic-based dental materials.

Keywords: layer-by-layer, diatomite, nanoceramics, zirconia $\left(\mathrm{ZrO}_{2}\right)$, dental materials

\section{Introduction}

Over the past 30 years, growing demand for highly esthetic and natural-looking dental restorations has led to the development of new all-ceramic dental materials with dramatically improved mechanical characteristics to increase their longevity. In particular, high-strength ceramics and related computer-aided design/computer-aided manufacturing (CAD/CAM) techniques have boosted clinical applications of metalfree prostheses with more favorable mechanical characteristics than earlier ceramic versions.

Zirconia $\left(\mathrm{ZrO}_{2}\right)$ is one of the most promising restorative materials, because of its favorable mechanical properties and reasonable esthetics. Nevertheless, it has many drawbacks, including some unfavorable esthetic characteristics, ${ }^{1,2}$ and the veneering ceramic has a tendency to chip during machining, ${ }^{3}$ making it a less-than-perfect material. The field of dentistry, therefore, requires new materials with favorable esthetic and mechanical properties that are also easy to machine.

Diatomite is a type of porous silicate with a large specific surface area, high absorption capacity, low density, and low cost (see Appendix). ${ }^{4,5}$ It shows excellent biocompatibility and can withstand the layer-by-layer (LBL) assembly process. ${ }^{6,7}$ These properties allow for versatile applications, including as an adsorbent for heavy metal 
ions or dyes, fillers, filter aids, and insulating materials. ${ }^{8-10}$ Diatomite has been used to fabricate high-strength porous ceramics. ${ }^{11}$ Thus, we investigated whether diatomite could be reinforced with nanoparticles to produce a new all-ceramic dental material with superior properties.

Fabricating nanocomposite ceramics with particles distributed within the matrix grains and along the grain boundaries can be difficult. The key to producing highperformance ceramic materials with high reliability lies in optimized processing. ${ }^{12}$ The particle size of the powders plays a critical role in determining the microstructure and mechanical properties of ceramics. ${ }^{13}$ Ideal powders have a small particle size and a narrow particle size distribution. However, as the particle size decreases, the powder tends to agglomerate. In this study, "agglomerates" are defined as weakly bonded particles that adhere together as a result of van der Waals forces, whereas "aggregates" are particles bonded together by solid bridges (typically formed during the calcination process). ${ }^{14}$ To overcome the problems associated with agglomerates, colloidal techniques have recently been used in ceramic processing. ${ }^{15}$ The use of dispersing agents to achieve a desired suspension rheology that facilitates subsequent processing is considered a better way to produce high-quality, high-performance, reliable ceramic products. However, polymer surfactants have been mainly used to modify single-phase ceramic powders ${ }^{16-20}$ and have rarely been reported in conjunction with multiphase ceramic powders (nanocomposite ceramic powders).

The LBL technique is used to construct nanometer-scale coatings using the driving force generated by the electrostatic attraction between opposite charges. The LBL technique allows for the deposition of homogeneous films with accurately controlled layer thickness and interlayer separation on arbitrarily shaped objects. The method involves alternately adsorbing polymers on a nano- or micro-sized charged substrate to form a multilayer polyelectrolyte. The LBL technique has a wide range of applications in the modification of structural and surface properties because of its ability to readily tailor particle properties (eg, size, composition, porosity, stability, surface functionality, and colloidal stability). ${ }^{21-24}$ Other advantages include the hybrid organicinorganic nature of the produced coatings; universality, with regard to both substrate and material to be deposited; and ease of implementation.

In this experiment, we modified diatomite-based ceramic powders using poly(allylamine hydrochloride) (PAH) and poly(sodium 4-styrenesulfonate) (PSS), adjusting the surface charge to help solve the problem of agglomeration.
Positively charged nano- $\mathrm{ZrO}_{2}$ particles were adsorbed onto diatomite particles with the aim of generating a microstructure that could help to improve the dispersion of the powder and the mechanical properties of the sintered ceramic bodies. The obtained ceramics were characterized and propagation phasecontrast synchrotron X-ray microtomography (PPCSR-CT) was used for the first time to examine the inner structure of the ceramics. The mechanical properties were also tested and compared with a control specimen, which was prepared by adding nano- $\mathrm{ZrO}_{2}$ to the unmodified diatomite particles. In addition, we sintered veneer porcelain to diatomite-based ceramics then compared their shear bond strengths with those of dental zirconium dioxide ceramics and IPS e.max (Ivoclar Vivadent AG, Schaan, Liechtenstein) ceramics.

\section{Materials and methods LBL modification}

To form high-quality diatomite-based ceramic powders, a diatomite:bentonite:quartz sand: $\mathrm{Na}_{2} \mathrm{CO}_{3}$ ratio of 11:4:4:1 was selected. The composite powder was dried after milling for 24 hours with the same amount of absolute ethanol. The diatomite-based powders were dipped in PAH $(\mathrm{Mw}=40,000 \mathrm{~g} / \mathrm{moL}$; Sigma-Aldrich, St Louis, $\mathrm{MO}$ ) solution at $\mathrm{pH}$, followed by dipping in $\mathrm{pH} 9$ PSS $(\mathrm{Mw}=70,000 \mathrm{~g} / \mathrm{moL}$; Sigma-Aldrich) solution. The $\mathrm{pH}$ values were determined by carefully measuring the zeta potential of the modified powders. The PAH and PSS solutions were $1 \mathrm{wt} \%$ and were prepared in deionized water at $2 \mathrm{mg} / \mathrm{mL}$ with $0.5 \mathrm{M} \mathrm{NaCl}$. The dipping time was 20 minutes, followed by repeated centrifugationredispersion cycles (10,000 rpm for 5 minutes), with each successive supernatant being carefully decanted and replaced with deionized water to ensure that all excess polyelectrolyte had been removed. ${ }^{22} \mathrm{~A}$ pH 3 nano- $\mathrm{ZrO}_{2}$ (3\% yttria-stabilized zirconia, $80 \mathrm{~nm}$; Tosoh, Tokyo, Japan) suspension, with positively charged surfaces, was adsorbed onto the negatively charged diatomite powders to produce a uniform structure. Figure 1 illustrates the fabrication process of LBL assembly of diatomite and nano- $\mathrm{ZrO}_{2}$.

Particle size distribution was measured (Mastersizer 2000, Malvern, UK) before and after modification. The functional groups on the particle surface were analyzed by X-ray photoelectron spectroscopy (XPS; ESCALAB 250, Thermo Scientific, Waltham, MA) at a pass energy of $20 \mathrm{eV}$, using the Al-K $\alpha$ line as the excitation source ( $\mathrm{hv}=1486.6 \mathrm{eV}$ ) at $150 \mathrm{~W}$. All binding energies reported were corrected using the signal for the carbonaceous impurities at $284.8 \mathrm{eV}$ as an internal standard. Scanning electron microscopy 


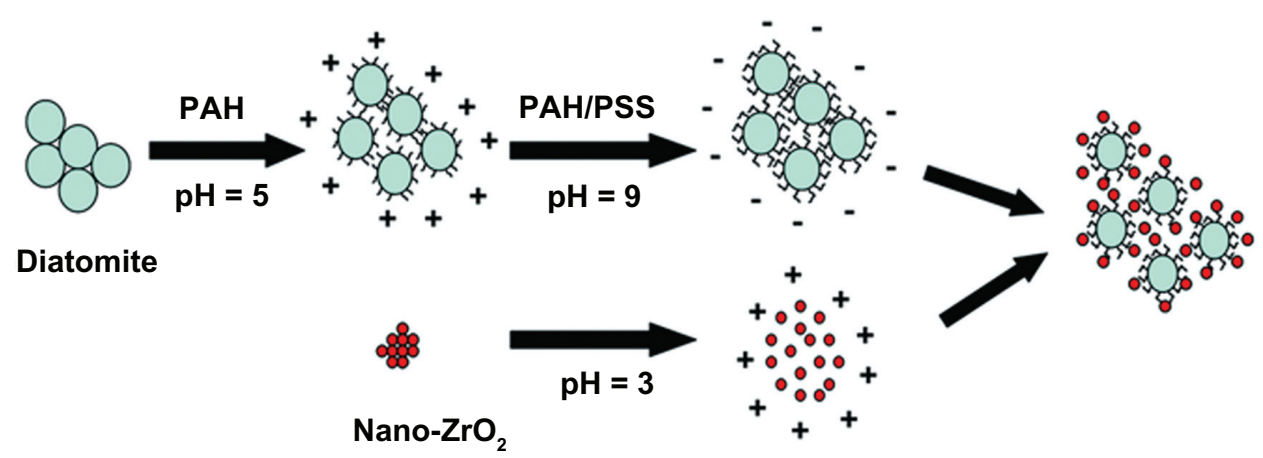

Figure I Schematic illustration of the fabrication process.

Note: After modification with PAH/PSS, diatomite particles were negatively charged and could adsorb positively charged nano-ZrO ${ }_{2}$. Abbreviations: PAH, poly(allylamine hydrochloride); PSS, poly(sodium 4-styrenesulfonate).

(SEM; JSM-5610LV, JEOL, Tokyo, Japan) was used to observe the dispersion of the diatomite-based powders and the adsorption condition of nano- $\mathrm{ZrO}_{2}$.

\section{Characterization of diatomite-based ceramics}

The diatomite-based powders modified by the LBL technique with $0,20,25,30$, and $35 \mathrm{wt} \%$ nano- $\mathrm{ZrO}_{2}$ were labeled $\mathrm{M} 0 \mathrm{Z}$, M20Z, M25Z, M30Z, and M35Z, respectively. Control specimens composed of the diatomite-based powders with nano- $\mathrm{ZrO}_{2}$ treated in deionized water devoid of PAH and PSS under the same conditions as the experimental groups were labeled U0Z, U20Z, U25Z, U30Z, and U35Z. Both groups were sintered at $1100^{\circ} \mathrm{C}$.

Sintered sample surfaces were polished and corroded in acetone for 20 seconds then cross-sections were observed by SEM and energy dispersive X-ray spectroscopy (JSM5610LV).

The open porosity of the sintered ceramics was measured by the Archimedes' method using the following equation: ${ }^{25}$

$$
P=\frac{M_{3}-M_{1}}{M_{3}-M_{2}}
$$

where $P$ is the percentage of open porosity, $M_{1}$ is the dry weight of the specimen in the air, $M_{2}$ is the saturated suspended weight of the specimen, and $M_{3}$ is the saturated weight of the specimen.

\section{Mechanical tests}

Sintered rectangular bars $(20 \times 4 \times 1.2 \mathrm{~mm})$ were polished and dried for the three-point bending test by ISO 6872 (span: $15 \mathrm{~mm}$, crosshead speed: $0.5 \mathrm{~mm} / \mathrm{min}$; Instron ${ }^{\circledR}$ Universal Testing Machine-3365, Norwood, MA). ${ }^{26}$
The Vickers hardness and fracture toughness were measured with a microhardness tester (HV-10B, Laizhou, YanTai, ShanDong, People's Republic of China) with an indentation load of $88.2 \mathrm{~N}$ and a load time of 15 seconds with the following parameters: ${ }^{27}$

$$
\begin{gathered}
H_{v}=1.854 P /(2 a)^{2} \\
K_{I C}=0.075 P c^{-3 / 2}
\end{gathered}
$$

where $P$ is the indentation load $(88.2 \mathrm{~N}), 2 a$ is the average length of the two diagonals of the indentation, and $c$ is the average length of the indentation center to the crack tip. The results were analyzed by analysis of variance test and Tukey's test. A $P$ value $<0.05$ was considered statistically significant.

U30Z and M30Z, which showed superior mechanical properties, were selected for PPCSR-CT and were imaged using a beamline of $13 \mathrm{~W}$ at the Shanghai Synchrotron Radiation Facility (Shanghai, People's Republic of China). We used an isotropic voxel size of $0.7 \mu \mathrm{m}$ and a beam monochromatized at an energy of $30 \mathrm{keV}$ using a multilayer monochromator. To obtain the phase-contrast effect, we used a sample-detector distance (propagation distance) of around $10 \mathrm{~cm}$, depending on the pixel size and 1500 projections on $180^{\circ}$.

\section{Shear bond strength test}

The shear bond strengths between the cores and veneers of the three groups, diatomite-based dental ceramics of M30Z (Dia group), zirconium dioxide dental ceramics (Zir group; Sirona Dental Systems GmbH, Bensheim, Germany), and IPS e.max (IPS group) ceramics were evaluated $(n=8)$. The veneer ceramics were sintered in Programat EP3000 (Ivoclar Vivadent $A G)$ in accordance with the manufacturer's instructions. Shear bond strength was calculated with a universal testing machine 
(Instron Universal Testing Machine-3365) by dividing the load at which failure occurred by the bonding area as follows: ${ }^{3}$

$$
P=\frac{F}{S}
$$

where $P$ is the shear bond strength (MPa), $F$ is the failure load $(\mathrm{N})$ and $S$ is the bonding area $\left(2 \times 3 \mathrm{~mm}^{2}\right)$. Load was applied parallel to the long axis of the specimen through a wedge at the core-veneer interface at a crosshead speed of $0.5 \mathrm{~mm} / \mathrm{min}$ until delamination of the veneering ceramic occurred. The results were analyzed using a one-way analysis of variance test $(P<0.05)$.

\section{Results}

\section{Modification effects of LBL assembly}

To establish the effect of polyelectrolyte dispersants on the dispersibility of the diatomite powder, we examined the size distribution of the diatomite particles. Before modification (Figure 2A), the size distribution of the diatomite particles was wide, from 0.2 to $90 \mu \mathrm{m}$, where $\mathrm{d}_{(0.5)}$ was $16.42 \mu \mathrm{m}$. After PAH/PSS modification, the particle size tended to become smaller, with the main peak shifting to the left, while the size range narrowed (from 0.12 to $35 \mu \mathrm{m}$ in Figure 2B); $\mathrm{d}_{(0.5)}$ decreased to $0.42 \mu \mathrm{m}$.

XPS is an ideal instrument with which to analyze the chemical state of surfaces in the successive assembly of PAH and PSS because of its high sensitivity and nondestructive nature. The survey scan XPS spectrum of the diatomite particles before modification is shown in Figure 3A, where the $\mathrm{Si} 2 \mathrm{p}, \mathrm{O} 1 \mathrm{~s}$ were detected at $102.66 \mathrm{eV}(2 \mathrm{p})$ and $532.05 \mathrm{eV}(1 \mathrm{~s})$. Figure 3B shows the survey scan XPS spectrum of PAH adsorbed on the negatively charged diatomite particles. A clear N1s signal is present at $399.55 \mathrm{eV}(1 \mathrm{~s})$ corresponding to the amine group of PAH. Figure $3 \mathrm{C}$ of the diatomite/PAH/PSS sample shows characteristic peaks at

A

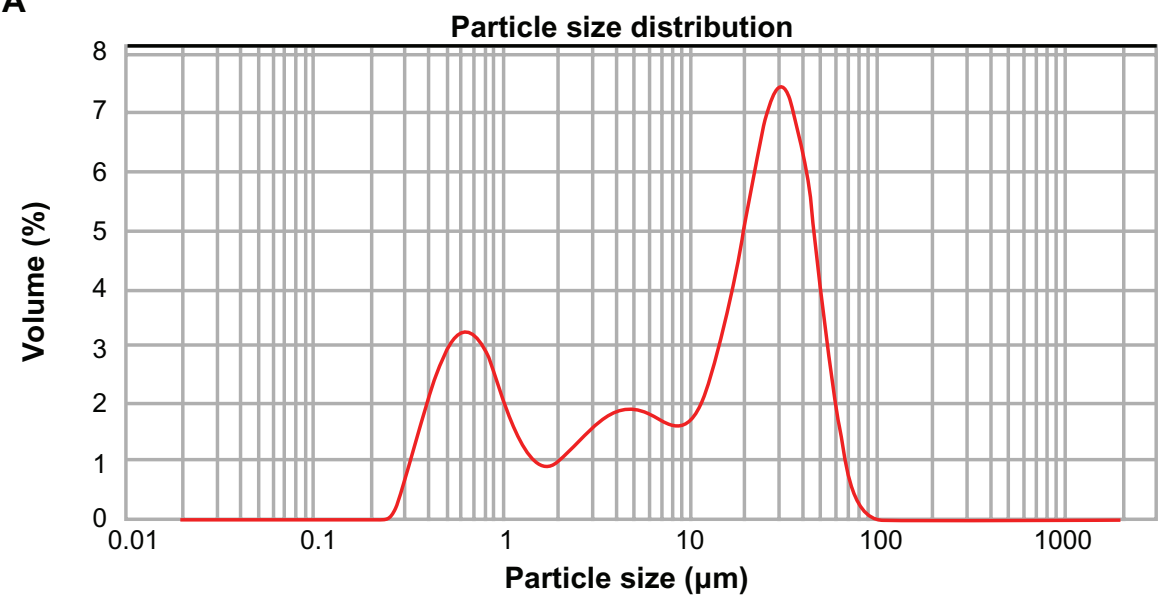

B

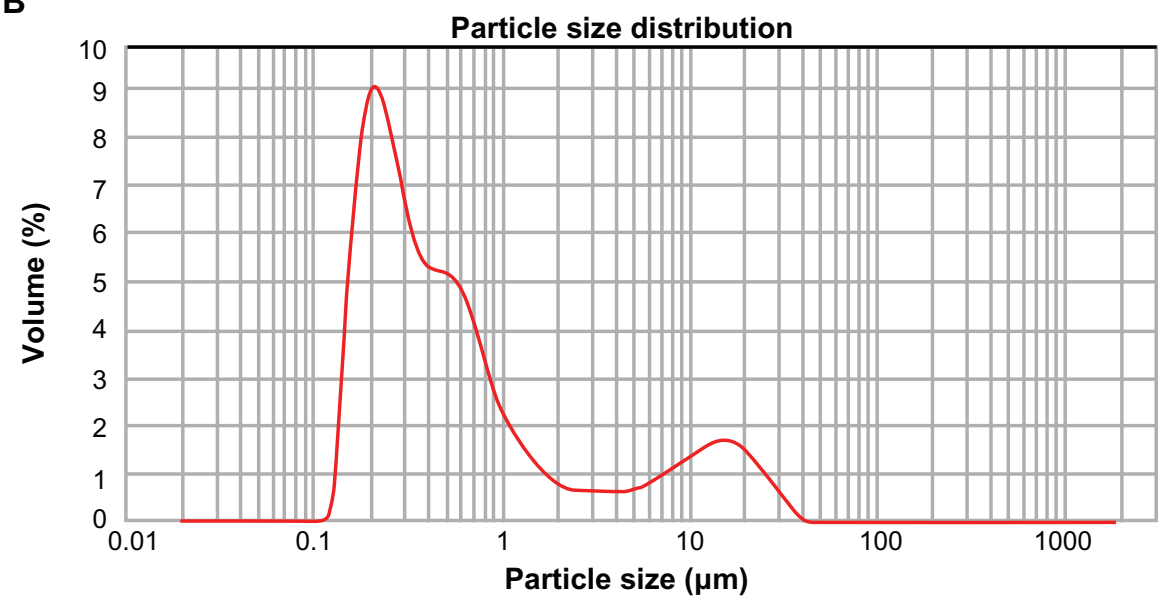

Figure 2 Size distribution of diatomite particles. (A) Before modification, the size distribution of diatomite particles spanned from 0.2 to $90 \mu \mathrm{m}$ and $\mathrm{d}_{(0.5)}$ was $16.42 \mu \mathrm{m}$. (B) After PAH/PSS modification, the diameter shifted to the left, size distribution narrowed (from 0.12 to $35 \mu \mathrm{m}$ ) and $\mathrm{d}_{(0.5)}$ decreased to $0.42 \mu \mathrm{m}$.

Abbreviations: PAH, poly(allylamine hydrochloride); PSS, poly(sodium 4-styrenesulfonate). 


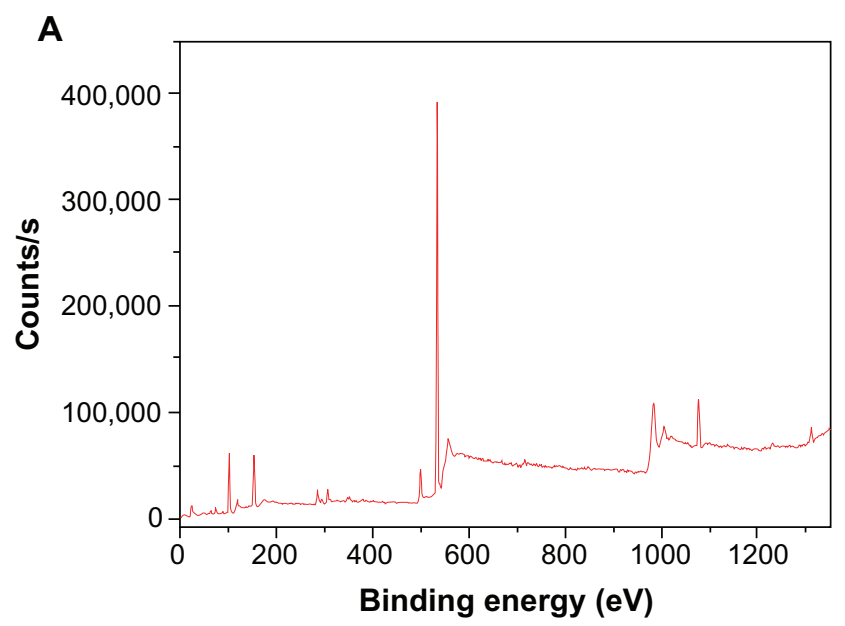

B

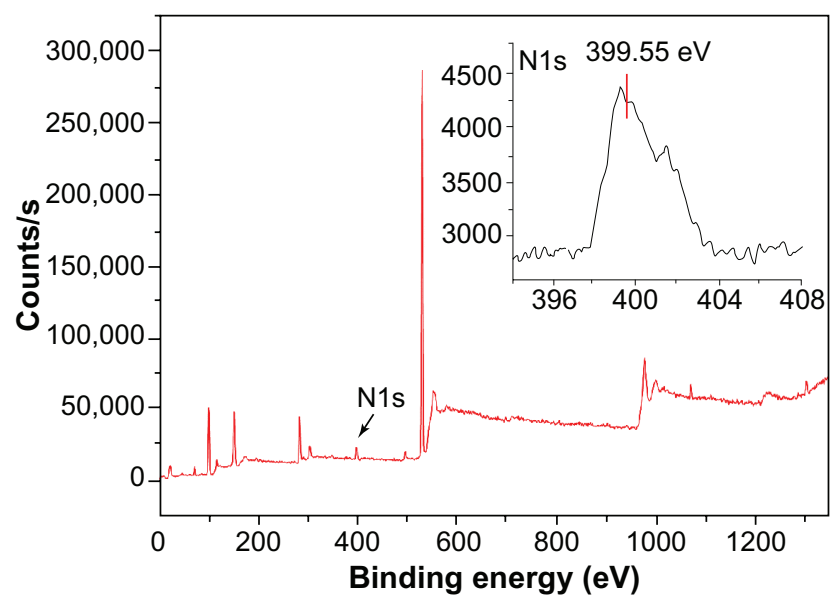

C

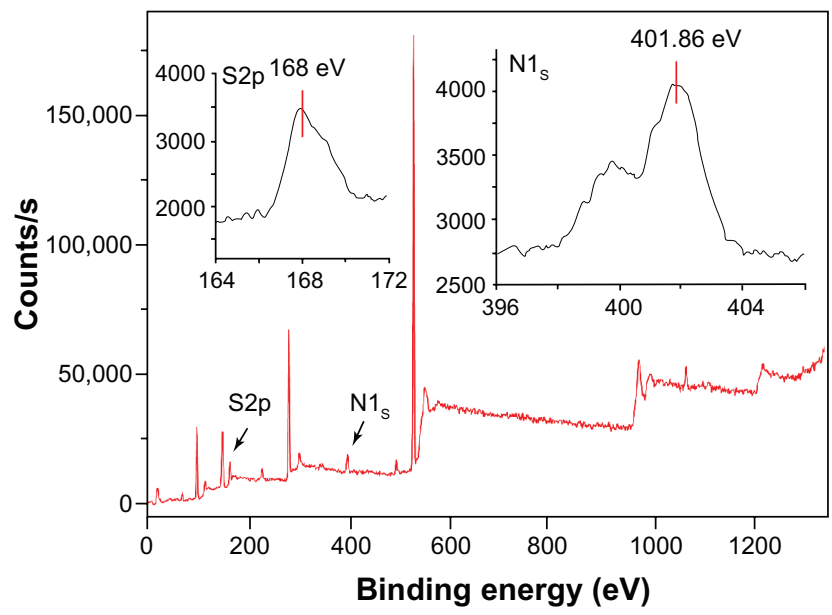

Figure $3 \mathrm{X}$-ray photoelectron spectroscopy spectrum of diatomite before and after modification. Before modification (A), Si2p and OIs were detected at $102.66 \mathrm{eV}(2 \mathrm{p})$ and $532.05 \mathrm{eV}(\mathrm{Is})$; after modification by $\mathrm{PAH}$ (B), a clear NIs signal was present at $399.55 \mathrm{eV}(\mathrm{Is})$, corresponding to the amine of PAH.

Note: After modification with PAH/PSS, the spectrum showed characteristic peaks of S2p at $168 \mathrm{eV}(\mathrm{S} 2 \mathrm{p})$, assigned to the sulfur of the sulfonate group of PSS.

Abbreviations: PAH, poly(allylamine hydrochloride); PSS, poly(sodium 4-styrenesulfonate).
$168 \mathrm{eV}(\mathrm{S} 2 \mathrm{p})$, assigned to the sulfur atom of the sulfonate group from the PSS polyelectrolyte. ${ }^{28}$

\section{SEM images of diatomite-based ceramic powders and sintered ceramics}

Diatomite-based composite dental ceramic powders without modification showed obvious agglomeration (Figure 4A); after modification, the agglomeration decreased. In addition, nano- $\mathrm{ZrO}_{2}$ particles were adsorbed around the diatomite powder, as marked by a circle in Figure 4B. The microstructures of sections of sintered diatomite-based nanocomposite ceramic bodies were also examined (Figure 5). During sintering, polymer surfactants were burned off, leaving only diatomite and nano- $\mathrm{ZrO}_{2}$ particles. The sintered body of unmodified diatomite-based powder containing $30 \mathrm{wt} \%$ nano- $\mathrm{ZrO}_{2}$ (U30Z; Figure $5 \mathrm{~A}$ ) showed a large volume of irregular pores. Furthermore, the unmodified ceramic particles agglomerated significantly (Figure 5B).
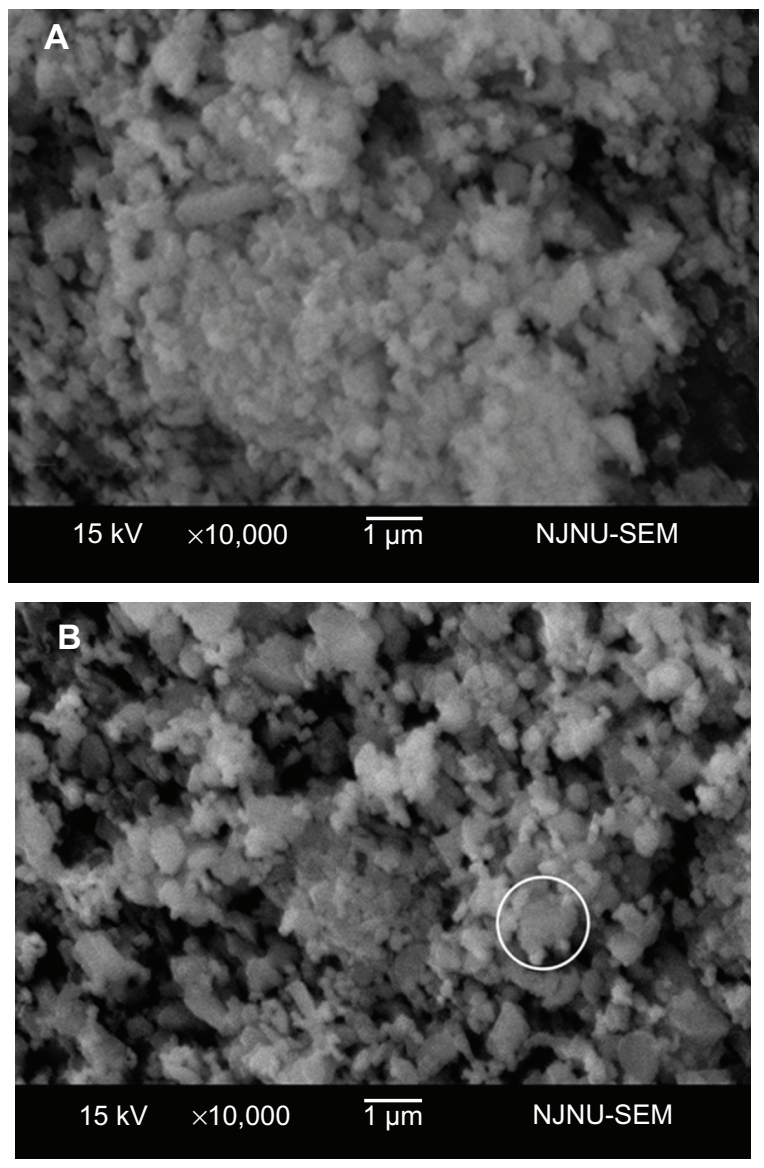

Figure 4 Scanning electron microscopy images of diatomite-based particles containing $30 \mathrm{wt} \%$ nano- $\mathrm{ZrO}_{2}$. (A) Image shows agglomeration of unmodified diatomite particles containing agglomerated nano- $\mathrm{ZrO}_{2}$. After modification (B), the diatomite particles are more uniformly distributed and nano- $\mathrm{ZrO}_{2}$ particles are adsorbed.

Note: A typical structure is circled in (B). 

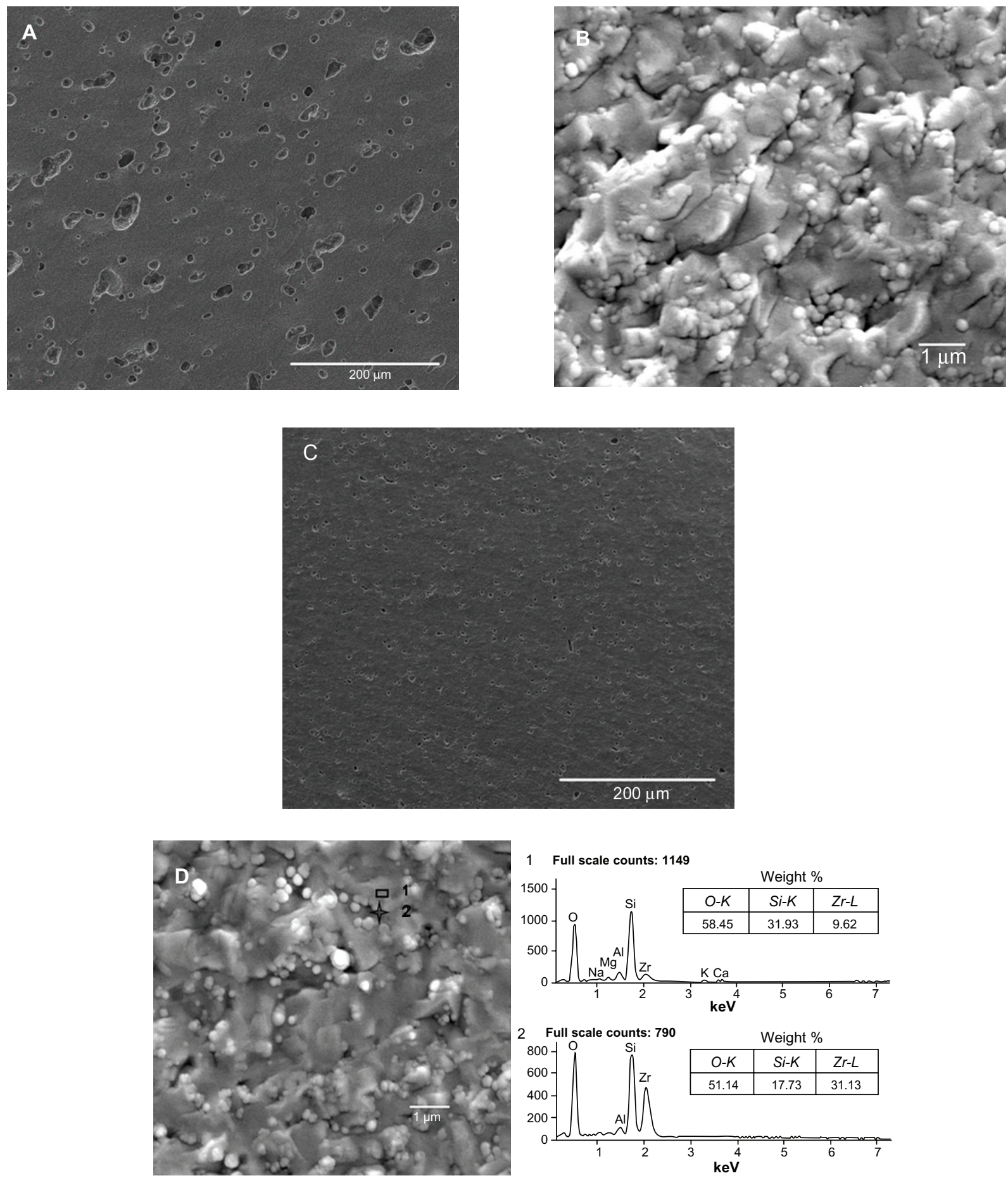

Figure 5 Scanning electron microscopy analysis of sections of the sintered ceramics. (A and $\mathbf{B})$ show sintered unmodified ceramics containing 30 wt\% nano- $\mathrm{ZrO},{ }_{2}(\mathrm{U} 30 \mathrm{Z})$, with a large volume of irregular pores. $(\mathbf{C}$ and $\mathbf{D})$ show sintered modified ceramics containing 30 wt\% nano- $\mathrm{ZrO}_{2}$ (M30Z). Compared with those shown in $(\mathbf{A}$ and $\mathbf{B})$, these ceramics exhibit high density with low porosity.

Note: The element of a typical structure was detected by EDS, confirming that it was composed of diatomite with adsorbed nano-ZrO ${ }_{2}$ particles.

However, in the cross-section of sintered-modified diatomitebased ceramics containing $30 \mathrm{wt} \%$ nano- $\mathrm{ZrO}_{2}(\mathrm{M} 30 \mathrm{Z})$, the porosity had obviously decreased, while well-distributed microcrystalline phases were found embedded in the amorphous matrix (Figure 5C). A uniformly dispersed structure of nano- $\mathrm{ZrO}_{2}$ adsorbed around diatomite particles was also observed (Figure 5D). The element of this structure was detected by energy dispersive $\mathrm{X}$-ray spectroscopy. The results showed that point 1 was mainly composed of silicon, while point 2 was mainly composed of zirconium, confirming the 
above results. Particle size decreased and agglomeration lessened after modification, leading to the formation of the compact green body shown in Figure 4B.

\section{Open porosity}

The open porosity values of the sintered ceramics in the modified group were statistically lower compared with those of the unmodified ones $(P<0.05)$. The porosity of both groups decreased with increasing levels of nano- $\mathrm{ZrO}_{2}$ (Figure 6). Before modification, the open porosity of U0Z showed a maximum of $3.15 \% \pm 0.63 \%$. After modification, M35Z showed a minimum of $0.10 \% \pm 0.06 \%$, indicating a near-perfect compact body. Open porosity declined because the particle size decreased and size distribution narrowed after modification. Smaller powders could more easily fill in the green body, so a more compact structure was formed. However, the volume of the closed pores of sintered dental porcelain could not be measured directly, so we combined the data with observations of the internal structure through SEM and PPCSR-CT to obtain a more detailed picture.

\section{Mechanical properties}

The mechanical properties of the modified and unmodified groups containing different amounts of nano- $\mathrm{ZrO}$ are shown in Figure 7. After modification, agglomeration decreased and nano- $\mathrm{ZrO}_{2}$ particles were adsorbed around the diatomite powder, which led to the formation of a compact green body. The mechanical properties of the modified sintered ceramic groups were statistically higher than those of the unmodified ones $(P<0.05)$. Flexural strength in the modified groups increased with increasing levels of nano- $\mathrm{ZrO}_{2}$, reaching a peak value of $276.80 \pm 16.27 \mathrm{MPa}$ when $30 \mathrm{wt} \%$ nano- $\mathrm{ZrO}_{2}$ was adsorbed (M30Z), and decreasing again when $35 \mathrm{wt} \%$ nano- $\mathrm{ZrO}_{2}$ was adsorbed (M35Z). The Vickers hardness of

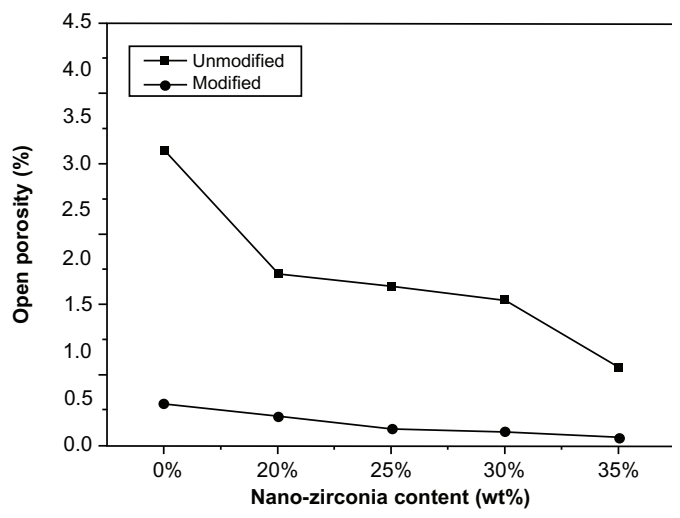

Figure 6 Open porosity of unmodified and modified diatomite-based nanocomposite sintered bodies containing $0,20,25,30$, and $35 \mathrm{wt} \%$ nano- $\mathrm{ZrO}_{2}$. Note: Open porosity declined after modification.
A
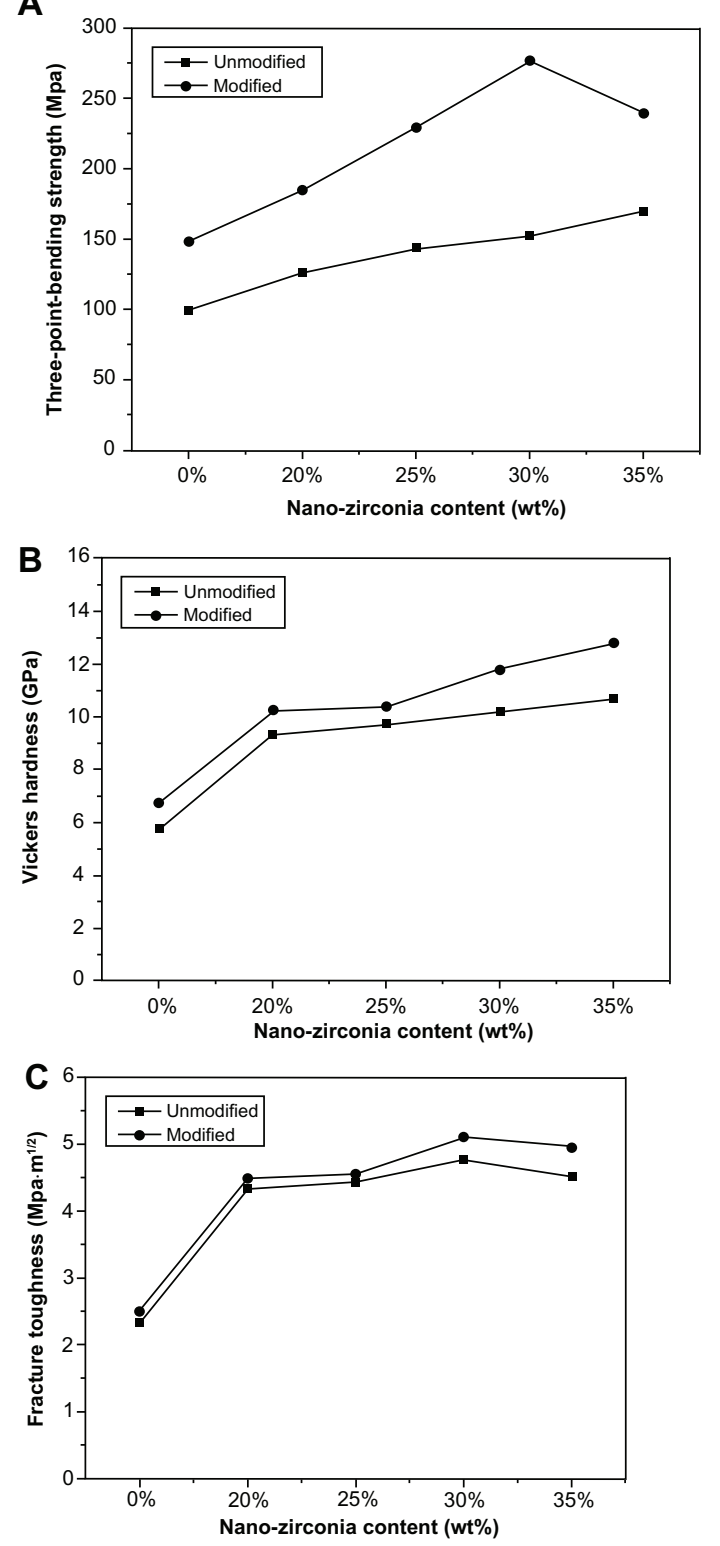

Figure 7 Mechanical properties of unmodified and modified diatomite-based nanocomposite sintered bodies containing 0, 20, 25, 30, and $35 \mathrm{wt} \%$ nano- $\mathrm{ZrO}_{2}$. (A) Flexural strength, (B) Vickers hardness, and (C) fracture toughness.

Note: Generally, the modified groups had better mechanical properties than the unmodified ones.

the modified groups was also statistically higher $(P<0.05)$, reaching a peak of $12.82 \pm 0.37 \mathrm{GPa}(\mathrm{M} 35 \mathrm{Z})$. The fracture toughness of modified groups improved $(P<0.05)$ and reached its highest level of $5.10 \pm 0.24 \mathrm{MPa} \mathrm{m}^{1 / 2}$ in M30Z.

\section{PPCSR-CT}

In this study, we attempted to determine the internal structure of the ceramics. Figure 8 shows 3D tomographic representations of $\mathrm{U} 30 \mathrm{Z}$ and $\mathrm{M} 30 \mathrm{Z}$ and their cross-section images from the $\mathrm{x}, \mathrm{y}$, and $\mathrm{z}$ axes. U30Z contained many pores, while no pores were visible to the naked eye on M30Z, 

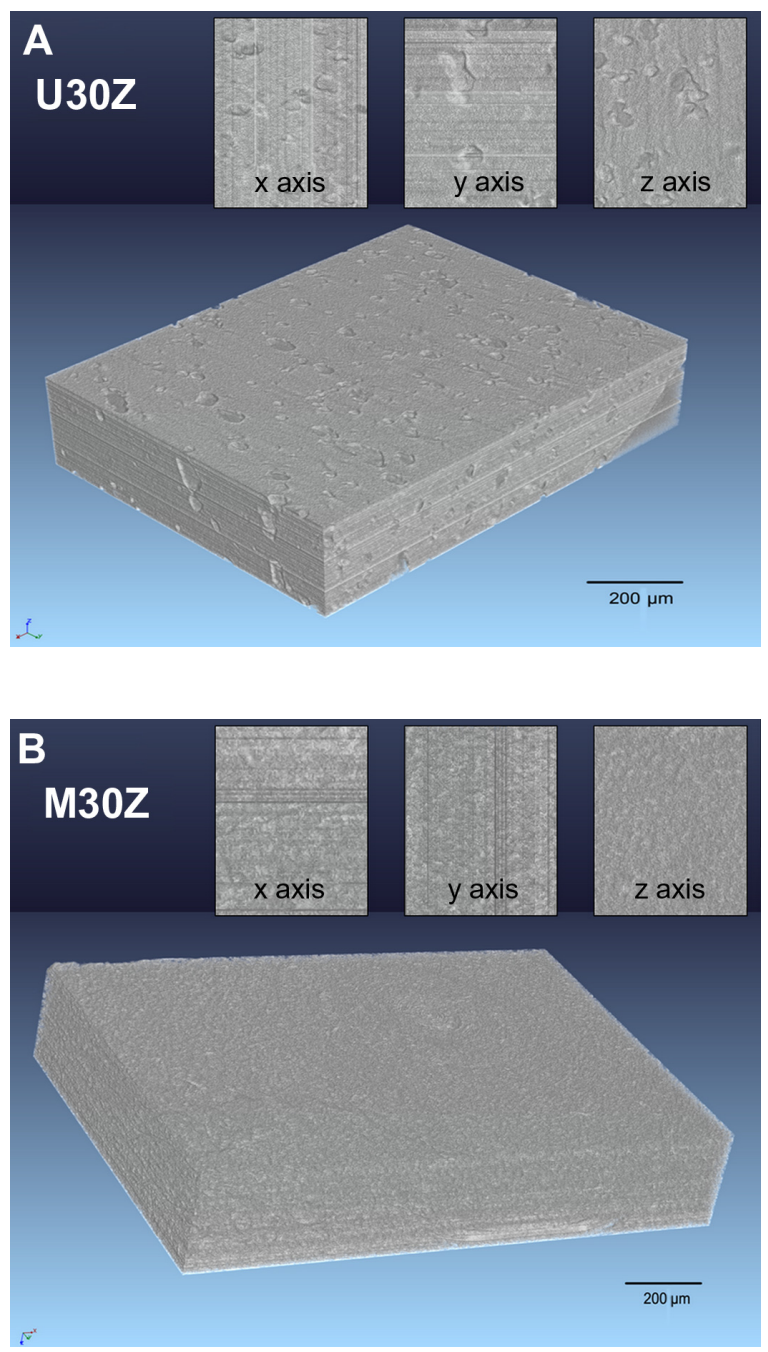

Figure 8 Three-dimensional phase-contrast synchrotron X-ray microtomography representations of $\mathrm{U} 30 \mathrm{Z}(\mathbf{A})$ and $\mathrm{M} 30 \mathrm{Z}$ (B) ceramics and their random cross-section images from $x, y$, and $z$ axes. A large number of holes are distributed in the sintered body of U30Z (A), while in M30Z, no pores are visible to the naked eye from the obtained images (B), indicating that the modification of ceramic powders by the layer-by-layer technique can significantly increase the density of the sintered body.

indicating that the modification of ceramic powders by the LBL technique can significantly increase the density of the sintered body. However, the current minimum pixel size in microtomography makes it difficult to carry out observations on the nanoscale. Indeed, small pores were still shown to be present by open porosity detection, leaving room for further improvement.

\section{Shear bond strength}

The results of shear bond strength were significantly different between the three groups $(P<0.05)$. The Dia group had the highest shear bond strength of $21.26 \pm 4.23 \mathrm{MPa}$. The average value in the IPS group was $14.07 \pm 4.28 \mathrm{MPa}$, while the Zir group had the lowest value of $6.85 \pm 1.11 \mathrm{MPa}$.

\section{Discussion}

Narrow size distribution powders give consistently more uniform and finer pore structures and are sintered to high density at relatively low temperatures with a uniform and fine-grained microstructure. ${ }^{15}$ Polyelectrolyte dispersants can contribute both static and steric stability at a certain $\mathrm{pH}$ to prevent the agglomeration of ceramic particles. Polyelectrolytes in solution can adsorb onto the powder surface, which changes the charge properties of the powder surface and the electrostatic repulsion among particles, as reflected by the increasing zeta potential. ${ }^{17,18}$ Thus, electrostatic repulsion is a well-known method of dispersion stabilization for both particles and polyelectrolytes. However, increasing the thickness of the polymer adsorption layer on the particle surface enhances the steric effects. ${ }^{29}$ Good stability is demonstrated through a synergistic effect between polymer dispersions.

We hypothesized that we could solve the problem of agglomeration of diatomite particles to form a uniformly dispersed nanocomposite ceramic powder by using polyelectrolyte dispersants, the LBL technique, and nano- $\mathrm{ZrO}_{2}$ particles. After LBL modification, the particle size of the diatomite powders decreased and the size distribution range narrowed; $\mathrm{d}_{(0.5)}$ decreased from 16.42 to $0.42 \mu \mathrm{m}$ (Figure 2). In addition, nano- $\mathrm{ZrO}_{2}$ particles, which showed a positive charge on the surface, were adsorbed around the negatively charged PAH/PSS-modified diatomite powders (Figure 4B). In this study, thicker coatings were not needed, so only twolayer polymer coatings were prepared. The smaller particle size is conducive to the formation of denser and more uniform diatomite/nano- $\mathrm{ZrO}_{2}$ composite ceramic powders, which can significantly improve the mechanical properties of ceramics.

To detect whether PAH/PSS polyelectrolyte had adsorbed onto the surface of the diatomite particles, we examined the particles by XPS. The XPS spectrum of the diatomite/PAH/ PSS sample revealed the presence of nitrogen from the amine groups of PAH linkers. Considering that the modification of the diatomite by PAH occurred because PAH has an amine group, a peak indicating the presence of nitrogen could be expected. ${ }^{30}$ The N1s peak at $399.55 \mathrm{eV}$ can be deconvoluted into two nitrogen species: a species that looks like an unprotonated amine at $399.2 \mathrm{eV}$ and the protonated amine $\left(\mathrm{NH}^{3+}\right)$ at $401.2 \mathrm{eV}$ in Figure 4B. The N1s peaks in Figure 4B and C shifted slightly from 399.55 to $401.86 \mathrm{eV}$. These results suggest that, first, the adsorption of PSS probably occurred by electrostatic interaction between the protonated amine of PAH and the negatively charged polyelectrolyte sulfonate groups. Secondly, the amine groups of PAH would be 
expected to be protonated at $\mathrm{pH}$ conditions of PSS adsorption (at pH 5, the amine groups of PAH are all accessible), while a fraction of the protonated amine groups of PAH that strongly interact with the sulfonate groups (possibly via H-bonding) would have a corresponding N1s peak at a lower binding energy than the amine groups not matched to sulfonates.

There may be several reasons why the mechanical properties of our ceramics were enhanced. First, the ceramic powders obtained after modification were composed of particles with a narrower size distribution and less agglomeration; the diatomite particles coated by nano- $\mathrm{ZrO}_{2}$ were homogeneous and could form a denser green body resulting in extremely greater mechanical properties nearly equal to those of conventional glass ceramics used in dental applications. ${ }^{26,31}$ As is the case for many high-performance ceramics, the strength of sintered ceramics can be increased by decreasing the porosity and number of flaws caused by processing. Secondly, the nano- $\mathrm{ZrO}_{2}$ particles adsorbed around the diatomite and embedded into the gaps could form a protective barrier to prevent the extension of cracks. ${ }^{32}$ Mechanical performance was further improved by crack deflection by mica plates and phase transformation of $\mathrm{ZrO}_{2}$ particles. Due to crack deflection and the inhibition of grain boundary sliding at elevated temperatures, Nano- $\mathrm{ZrO}_{2}$ is a toughening material with excellent mechanical properties at ambient temperatures. ${ }^{33-36}$

Flexural strength was highest in M30Z, decreasing in $\mathrm{M} 35 \mathrm{Z}$ when levels of nano- $\mathrm{ZrO}_{2}$ rose further; this might be because the excess nano- $\mathrm{ZrO}_{2}$ could not be adsorbed on the surface of the diatomite or packed into the gaps but instead agglomerated, resulting in an uneven density and reduced strength. In unmodified groups, there was nearly no adsorption of nano- $\mathrm{ZrO}_{2}$, only mechanical mixture. The fracture toughness of modified groups was somewhat improved, reaching a peak of $5.10 \pm 0.24 \mathrm{MPa} \mathrm{m}^{1 / 2}$ in M30Z. From a practical standpoint, microstructural effects were found to be important, but only within a limited range; the chemistry appeared to define the band of achievable property values. $^{37}$

The traditional method for microstructure characterization is SEM, which offers the advantage of precision for nanometer-scale microstructures. However, it can only show a single $2 \mathrm{D}$ cross-sectional view of the interior of the specimen. Observations of internal structures are very important for ceramic materials because the dispersion of internal sintered compounds, porosity, and pore volume are essential to the study of ceramics. X-ray synchrotron microtomography is a nondestructive technique for visualizing features from any vantage point, visualizing internal characteristics in virtual cross-sections in any plane, and generating 3D virtual extractions of internal structures useful for the analysis of a wide range of materials including rock, bone, ceramic, metal, and soft tissue. ${ }^{38-41}$ The contrast in absorption tomography is related to the density of the material, and thus different material phases can be distinguished. Pores in the ceramic sintered body should have a low density, which can be clearly observed from the 3D image (Figure 8).

Since adhesion of the veneering ceramic to the ceramic substructure is key to the successful performance of veneer/ core bilayered restorations, the initial bond strength can provide useful information on the behavior and predictability of all-ceramic systems in clinical applications. The diatomite-based substrate ceramic of M30Z after LBL modification (Dia group) statistically showed the highest mean shear bond strength of $21.26 \pm 4.23 \mathrm{MPa}$ compared with the other clinical all-ceramic materials $(P<0.05)$. Unmodified diatomite-based dental ceramics were not included in this study, as they did not meet the basic strength requirements of clinical substrate ceramics. Many variables can affect the core-veneer bond strength, such as residual stresses generated by a mismatch in the thermal expansion coefficient, flaws and structure defects at the core-veneer interface, and wetting properties and volumetric shrinkage of the veneer. ${ }^{42,43}$ Usually, the core-veneer bond or the veneering material itself has to be strong enough to withstand the stresses of mastication to prevent delamination and fracture of the veneering material. Experimental veneer with a higher thermal expansion coefficient resulted in massive fractures in both the core and veneering material. Failures occur, in part, because of transient and residual stress concentrations at the core-veneer interface that are formed during cooling. Residual stresses can assist the propagation of micro-cracks along the interface, significantly decreasing the bond strength or causing veneer delamination or chipping. ${ }^{44}$ As a silicate ceramic, diatomite contains the same ingredients as veneering porcelain, which may help to form a chemical bond between them. If a good chemical match between the core and veneer porcelain can be obtained, the structure should be able to withstand not only transient and residual stresses but also the greater forces of functional processes. In our next study, we will further investigate the nature of the interface between the diatomitebased dental ceramic and the veneering porcelain.

\section{Conclusion}

The agglomeration of diatomite-based powders improved with the use of the LBL technique, which led to a significantly smaller particle size and a narrower size distribution. 
After modification, the surface of the diatomite-based powder was negatively charged, thus, could adsorb positively charged nano- $\mathrm{ZrO}_{2}$ particles to improve the sintered ceramics. A highly dense microstructure was obtained and the mechanical properties of the modified diatomite-based nanocomposite ceramics were significantly improved. The shear bond strength of the diatomite-veneer ceramic was statistically higher than that of other clinical all-ceramic dental materials.

\section{Acknowledgments}

The authors would like to express their appreciation to Professor Qinghong Zhang (Donghua University) for his helpful discussions, Professor Tianzhu Zhang (Southeast University) for his excellent technical assistance, and Dr Zongjun Yin (Nanjing Institute of Geology and Palaeontology, Chinese Academy of Sciences) for his help in the PPCSR-CT analysis. This work was supported by grants from the Priority Academic Program Development of Jiangsu Higher Education Institutions (PAPD), National High Technology Research and Development Program 863 (2012AA030309), the Outstanding Medical Academic Leader Program and Creative Team of Jiangsu Province (2011048), the Natural Science Fund Association of Jiangsu Province (BK 2009137), and the Industrialization Project of High and New Technology of Education department in Jiangsu Province (JH 10-27).

\section{Disclosure}

The authors declare no conflicts of interest in this work.

\section{References}

1. Chen YM, Smales RJ, Yip KH, Sung WJ. Translucency and biaxial flexural strength of four ceramic core materials. Dent Mater. 2008; 24(11):1506-1511.

2. Baldissara P, Llukacej A, Ciocca L, Valandro FL, Scotti R. Translucency of zirconia copings made with different CAD/CAM systems. J Prosthet Dent. 2010;104(1):6-12.

3. Guess PC, Kulis A, Witkowski S, et al. Shear bond strengths between different zirconia cores and veneering ceramics and their susceptibility to thermocycling. Dent Mater. 2008;24(11):1556-1567.

4. Losic D, Mitchell JG, Voelcker NH. Diatomaceous lessons in nanotechnology and advanced materials. Adv Mater. 2009;21(29):2947-2958.

5. San O, Gören R, Özgür C. Purification of diatomite powder by acid leaching for use in fabrication of porous ceramics. Int J Miner Process. 2009;93(1):6-10.

6. Hadjadj-Aoul O, Belabbes R, Belkadi M, Guermouche M. Characterization and performances of an Algerian diatomite-based gas chromatography support. Appl Surf Sci. 2005;240(1-4):131-139.

7. Ediz N, Bentli I, Tatar I. Improvement in filtration characteristics of diatomite by calcination. Int J Miner Process. 2010;94(3-4):129-134.

8. Sheng G, Hu J, Wang X. Sorption properties of Th (IV) on the raw diatomite - Effects of contact time, $\mathrm{pH}$, ionic strength and temperature. Appl Radiat Isot. 2008;66(10):1313-1320.

9. Liu Y, Zheng S, Du GX, Shu F, Chen JT. Photocatalytic degradation property of nano- $\mathrm{TiO}_{2}$ /diatomite for rodamine $\mathrm{B}$ dye wastewater. Int J Mod Phys B. 2009;6(7):1683-1688.
10. Liang J. Impact fracture toughness and morphology of diatomitefilled polypropylene composites. Polym Eng Sci. 2009;49(8): 1603-1607.

11. Akhtar F, Rehman Y, Bergstrom L. A study of the sintering of diatomaceous earth to produce porous ceramic monoliths with bimodal porosity and high strength. Powder Technol. 2010;201(3):253-257.

12. Huang Q, Chen P, Gu M, Jin Y, Sun K. Effect of surface modification on the rheological behavior of concentrated, aqueous $\mathrm{SiC}$ suspensions. Mater Lett. 2002;56(4):546-553.

13. Zhu S, Fahrenholtz WG, Hilmas GE. Influence of silicon carbide particle size on the microstructure and mechanical properties of zirconium diboride-silicon carbide ceramics. J Eur Ceram Soc. 2007;27(4):2077-2083.

14. Balakrishnan A, Pizette P, Martin C, Joshi S, Saha B. Effect of particle size in aggregated and agglomerated ceramic powders. Acta Mater. 2010;58(3):802-812.

15. Ma J, Lim L. Effect of particle size distribution on sintering of agglomerate-free submicron alumina powder compacts. J Eur Ceram Soc. 2002;22(13):2197-2208.

16. Liu DM. Influence of dispersant on powders dispersion and properties of zirconia green compacts. Ceram Int. 2000;26(3):279-287.

17. Tang F, Huang X, Zhang Y, Guo J. Effect of dispersants on surface chemical properties of nano-zirconia suspensions. Ceram Int. 2000;26(1):93-97.

18. Xie Z, Ma J, Xu Q, Huang Y, Cheng YB. Effects of dispersants and soluble counter-ions on aqueous dispersibility of nano-sized zirconia powder. Ceram Int. 2004;30(2):219-224.

19. Krnel K, Sciti D, Landi E, Bellosi A. Surface modification and oxidation kinetics of hot-pressed AlN-SiC-MoSi ${ }_{2}$ electroconductive ceramic composite. Appl Surf Sci. 2003;210(3-4):274-285.

20. Völtzke D, Abicht HP, Woltersdorf J, Pippel E. Surface modification of pre-sintered $\mathrm{BaTiO}_{3}$ particles. Mater Chem Phys. 2002; 73(2-3):274-280.

21. Johnston APR, Cortez C, Angelatos AS, Caruso F. Layer-by-layer engineered capsules and their applications. Curr Opin Colloid Interface Sci. 2006;11(4):203-209.

22. Zhu H, McShane MJ. Macromolecule encapsulation in diazoresinbased hollow polyelectrolyte microcapsules. Langmuir. 2005;21(1): 424-430.

23. Petrov A, Gavryushkin A, Sukhorukov G. Effect of temperature, $\mathrm{pH}$ and shell thickness on the rate of $\mathrm{Mg}^{2+}$ and $\mathrm{Ox}^{2-}$ release from multilayered polyelectrolyte shells deposited onto microcrystals of magnesium oxalate. J Phys Chem B. 2003;107(3):868-875.

24. Kim BS, Lebedeva OV, Kim DH, et al. Assembly and mechanical properties of phosphorus dendrimer/polyelectrolyte multilayer microcapsules. Langmuir. 2005;21(16):7200-7206.

25. Appoloni CR, Pottker WE. Non-destructive porosity profile measurement of amorphous materials by gamma-ray transmission. Appl Radiat Isot. 2004;61(6): 1133-1138.

26. Guazzato M, Albakry M, Ringer SP, Swain MV. Strength, fracture toughness and microstructure of a selection of all-ceramic materials. Part I. Pressable and alumina glass-infiltrated ceramics. Dent Mater. 2004;20(5):441-448.

27. Nevarez-Rascon A, Aguilar-Elguezabal A, Orrantia E, BocanegraBernal M. On the wide range of mechanical properties of ZTA and ATZ based dental ceramic composites by varying the $\mathrm{Al}_{2} \mathrm{O}_{3}$ and $\mathrm{ZrO}_{2}$ content. Int J Refract Met Hard Mater. 2009;27(6):962-970.

28. Morales-Cruz AL, Fachini ER, Miranda FA, Cabrera CR. Surface analysis monitoring of polyelectrolyte deposition on $\mathrm{Ba}_{0.5} \mathrm{Sr}_{0.5} \mathrm{TiO}_{3}$ thin films. Appl Surf Sci. 2007;253(22):8846-8857.

29. Cai K, Ode M, Murakami H. Influence of polyelectrolyte dispersants on the surface chemical properties of aluminum in aqueous suspension. Colloids Surf A Physicochem Eng Asp. 2006;284:458-463.

30. Wang L, Jiang M, Wang E, et al. Synthesis and characterization of the nanoporous ultrathin multilayer films based on molybdenum polyoxometalate (Mo36) n. Mater Lett. 2004;58(5):683-687. 
31. Guazzato M, Albakry M, Ringer SP, Swain MV. Strength, fracture toughness and microstructure of a selection of all-ceramic materials. Part II. Zirconia-based dental ceramics. Dent Mater. 2004;20(5):449-456.

32. Benzaid R, Chevalier J, Saadaoui M, et al. Fracture toughness, strength and slow crack growth in a ceria stabilized zirconiaalumina nanocomposite for medical applications. Biomaterials. 2008;29(27):3636-3641.

33. Apel E, van't Hoen $\mathrm{C}$, Rheinberger V, Holand W. Influence of $\mathrm{ZrO}_{2}$ on the crystallization and properties of lithium disilicate glassceramics derived from a multi-component system. J Eur Ceram Soc. 2007;27(2-3):1571-1577.

34. Bamba N, Choa YH, Sekino T, Niihara K. Mechanical properties and microstructure for $3 \mathrm{~mol} \%$ yttria doped zirconia/silicon carbide nanocomposites. J Eur Ceram Soc. 2003;23(5):773-780.

35. Montazerian M, Alizadeh P, Eftekhari Yekta B. Pressureless sintering and mechanical properties of mica glass-ceramic/Y-PSZ composite. J Eur Ceram Soc. 2008;28(14):2687-2692.

36. Oelgardt C, Anderson J, Heinrich J, Messing G. Sintering, microstructure and mechanical properties of $\mathrm{Al}_{2} \mathrm{O}_{3}-\mathrm{Y}_{2} \mathrm{O}_{3}-\mathrm{ZrO}_{2}(\mathrm{AYZ})$ eutectic composition ceramic microcomposites. J Eur Ceram Soc. 2010;30(3):649-656.

37. Quinn J, Sundar V, Lloyd I. Influence of microstructure and chemistry on the fracture toughness of dental ceramics. Dent Mater. 2003;19(7):603-611.
38. Friis EM, Crane PR, Pedersen KR, et al. Phase-contrast X-ray microtomography links Cretaceous seeds with Gnetales and Bennettitales. Nature. 2007;450(7169):549-552.

39. Smith TM, Olejniczak AJ, Tafforeau P, et al. Molar crown thickness, volume, and development in South African Middle Stone Age humans. S Afr J Sci. 2006;102(11/12):513.

40. Tafforeau P, Boistel R, Boller E, et al. Applications of X-ray synchrotron microtomography for non-destructive $3 \mathrm{D}$ studies of paleontological specimens. Appl Phys A. 2006;83(2):195-202.

41. Tafforeau P, Smith TM. Nondestructive imaging of hominoid dental microstructure using phase contrast X-ray synchrotron microtomography. J Hum Evol. 2008;54:272-278.

42. Isgrò G, Pallav P, van der Zel JM, Feilzer AJ. The influence of the veneering porcelain and different surface treatments on the biaxial flexural strength of a heat-pressed ceramic. J Prosthet Dent. 2003; 90(5):465-473.

43. Al-Shehri SA, Mohammed H, Wilson CA. Influence of lamination on the flexural strength of a dental castable glass ceramic. J Prosthet Dent. 1996;76(1):23-28.

44. Della Bona A, Van Noort R. Shear vs tensile bond strength of resin composite bonded to ceramic. J Dent Res. 1995;74(9):1591. 


\section{Appendix}

Diatomaceous earth has recently attracted a great deal of attention from industry because of its abundance, low cost, and the unique structure of diatom shells. Our research group developed a new type of diatomite-based machinable dental ceramics in 2008 (China patent 200910115734.3).

\section{Publish your work in this journal}

The International Journal of Nanomedicine is an international, peerreviewed journal focusing on the application of nanotechnology in diagnostics, therapeutics, and drug delivery systems throughout the biomedical field. This journal is indexed on PubMed Central, MedLine, CAS, SciSearch $\AA$, Current Contents ${ }^{\circledR} /$ Clinical Medicine,
Journal Citation Reports/Science Edition, EMBase, Scopus and the Elsevier Bibliographic databases. The manuscript management system is completely online and includes a very quick and fair peer-review system, which is all easy to use. Visit http://www.dovepress.com/ testimonials.php to read real quotes from published authors. 